\title{
Larval development of Hexapanopeus caribbaeus (Stimpson, 1871) (Crustacea, Decapoda, Xanthoidea, Panopeidae) reared under laboratory conditions
}

\author{
R. R. R. VIEIRA ${ }^{1 *}$ AND P. J. RIEGER ${ }^{2}$ \\ I'LABORATÓRIO CRUSTÁCEOS DECÁPODOS, DEPARTAMENTO OCEANOGRAFIA, FUNDAÇÃO UNIVERSIDADE FEDERAL DO RIO GRANDE, C. POSTAL 474, \\ RIO GRANDE, CEP 9620I-900, RS, BRASIL AND ${ }^{2}$ LABORATÓRIO ZOOLOGIA CRUSTACEA DECAPODA, DEPARTAMENTO CIÊNCIAS \\ MORFO-BIOLÓGICAS, FUNDAÇÃO UNIVERSIDADE FEDERAL DO RIO GRANDE, C. POSTAL 474, RIO GRANDE, CEP 962OI-9OO, RS, BRASIL \\ *CORRESPONDING AUTHOR: pgobrony@furg.br
}

Received on April 2, 2003; accepted on June 3, 2004; published online on August 3, 2004

The genus Hexapanopeus Rathbun, 1898 contains eight species, of which three are found in the Brazilian coast. The larval development of two of these species has already been studied in the laboratory. This article describes in detail the morphology of the complete larval stages of Hexapanopeus caribbaeus reared under laboratory conditions, and the morphology is compared with that of the larvae of the other species of the same genus.

\section{INTRODUGTION}

The Xanthoidea MacLay, 1838 sensu stricto includes 11 families (Martin and Davis, 2001), with approximately 1000 species distributed over 130 genera (Rice, 1980). Twenty-seven genera of this superfamily occur in the southwestern Atlantic (Pohle et al., 1999; Felder and Martin, 2003), comprising 53 species. The family Panopeidae is composed of eight genera, and the genus Hexapanopeus Rathbun, 1898 comprises eight species, of which three are found in the Brazilian coast (Schubart et al., 2000; Felder and Martin, 2003).

Hexapanopeus caribbaeus (Stimpson, 1871) is distributed in the western Atlantic, the Antilles, north of South America and Brazil (from the State of Pará to Rio Grande do Sul) (de Melo, 1996; Rieger et al., 1996). It inhabits mainly mud grounds, occurring from the shoreline to a depth of $55 \mathrm{~m}$ (de Melo, 1996).

The larval development of Xanthoidea in the southwestern Atlantic was studied by rearing 25 species under laboratory conditions. For the genus Hexapanopeus, a complete larval development has been published for Hexapanopeus angustifrons and Hexapanopeus paulensis (Costlow and Bookhout, 1966; Fransozo et al., 1990). This article describes in detail the morphology of the complete larval stages of the panopeid crab $H$. caribbaeus reared under laboratory conditions. A comparison of larval morphology is given for the larvae of other species of the same genus already studied.

\section{METHOD}

Hexapanopeus caribbaeus ovigerous females were collected manually in 1997 at the Ponte dos Franceses $\left(32^{\circ} 04^{\prime} 00^{\prime \prime}\right.$ S; 052 $04^{\prime} 12^{\prime \prime}$ W) Rio Grande, RS, Brazil, during low tide, in the mud under stones of places under freshwater influence. In the laboratory, the females were isolated in tanks with $10 \mathrm{~L}$ of filtered seawater, with salinity at 35 and continuous aeration until larval eclosion. The females were not fed during this period. After eclosion, which occurred at night, 57 larvae were selected from among those most active. They were removed from the tanks with a pipette and put separately into $50 \mathrm{~mL}$ plastic jars with $20 \mathrm{~mL}$ of seawater at salinity 35, with Bezil penicillin potassium $02 \mathrm{mg}^{-1}$. Then, they were placed in a BOD eletrolab climatic chamber with a temperature of $25 \pm 1^{\circ} \mathrm{C}$ and a photoperiod of $12 \mathrm{~h}$ of light and $12 \mathrm{~h}$ of dark.

The experiments were monitored daily to register mortality and verify ecdysis. Then, the larvae were removed and the jar was washed with fresh water. The larvae were then fed with rotifers Brachionus plicatilis Muller, 1786 (that had grown on Tetraselmis sp. Stein, 
1878) for the first stage of zoea and five Artemia sp. nauplii per jar for the second stage. The larvae which died during the experiment and exuviae were fixed in $96 \%$ ethanol and glycerine mixture, at ratio of $1: 1$ (vol:vol). [For the terminology adopted and the laboratory routine used, see (Ingle, 1992; Rieger, 1997; Rieger and Vieira, 1997; Clark et al., 1998.)]

All appendages were dissected using a tungsten wire electrolytically sharpened in a $10 \% \mathrm{KOH}$ solution. Drawings were done on 10 larvae and/or exuviae per stage, using an Olympus BX-50 microscope with Nomarski interference contrast, equipped with a camera lucida. The long plumose setae on the distal exopod segments of the first and second maxilliped and aesthetascs on antennule are not fully illustrated, but they are drawn truncated. The numbers in parentheses indicate a low frequency of occurrence.

\section{RESULTS}

The larvae have total eclosion, developing during four zoea stages and one megalopa stage. The pre-zoea stage was not found. Forty-seven larvae reached the megalopa stage out of 57 initially separated. Zoeal development was completed in a minimum of 10 days from hatching. The first crab appeared at 16 days after hatching. The maximum, minimum and average duration of each stage is summarized in Table I, and the number and duration of larval stages are shown in Figure 1.

\section{Descriptions}

\section{Zoea I}

Carapace (Figure 2a): Globose, with dorsal spine slightly curved without spines or setae. Rostral spine present, as long as protopod of antenna without spines or setae.

\section{Table I: Hexapanopeus caribbaeus}

\begin{tabular}{lccccc}
\hline & Zoea I & Zoea II & Zoea III & Zoea IV & Megalopa \\
\hline $\begin{array}{l}\text { Accumulated average } \\
\text { duration (in days) }\end{array}$ & 3 & 5.41 & 8.08 & 11.85 & 18 \\
$\begin{array}{l}\text { Minimum duration } \\
\text { Maximum duration }\end{array}$ & 7 & 4 & 7 & 10 & 16 \\
Number of alive & 50 & 48 & 47 & 47 & 26 \\
$\quad$ individuals & 7 & 2 & 1 & - & 21 \\
Number of dead & & & & & \\
$\quad$ individuals & 87.1 & 84.21 & 82.45 & 82.45 & 47 \\
Survival percentage & & & & & \\
\end{tabular}

Duration and survival of the larval stages starting from the hatching.

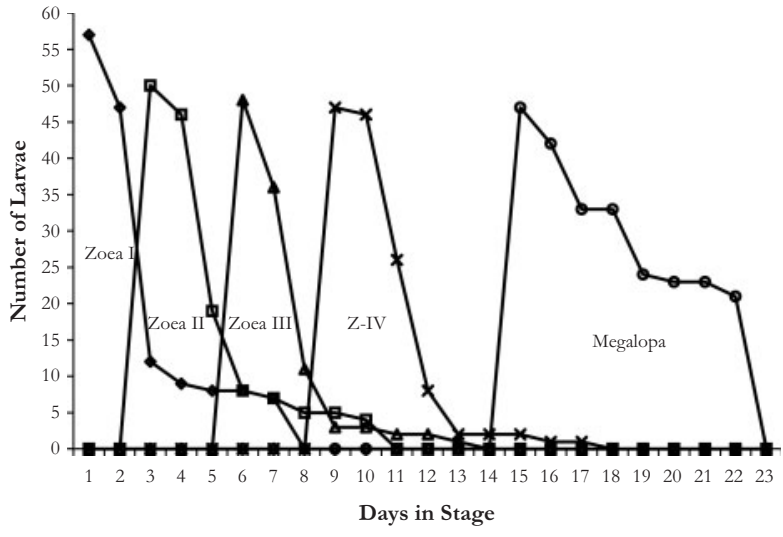

Fig. 1. Number and duration of larval stages of Hexapanopeus caribbaeus (Stimpson, 1871) reared under laboratory conditions.

Lateral spines present, very reduced. One pair of anterodorsal setae. Eyes sessile.

Abdomen (Figure 3a): Five somites and telson. Somite 1 naked; somite 2 with a pair of dorsolateral spines; somite 4 with small posterolateral projection that recovers the initial part of the fifth somite. Somite 5 with a long

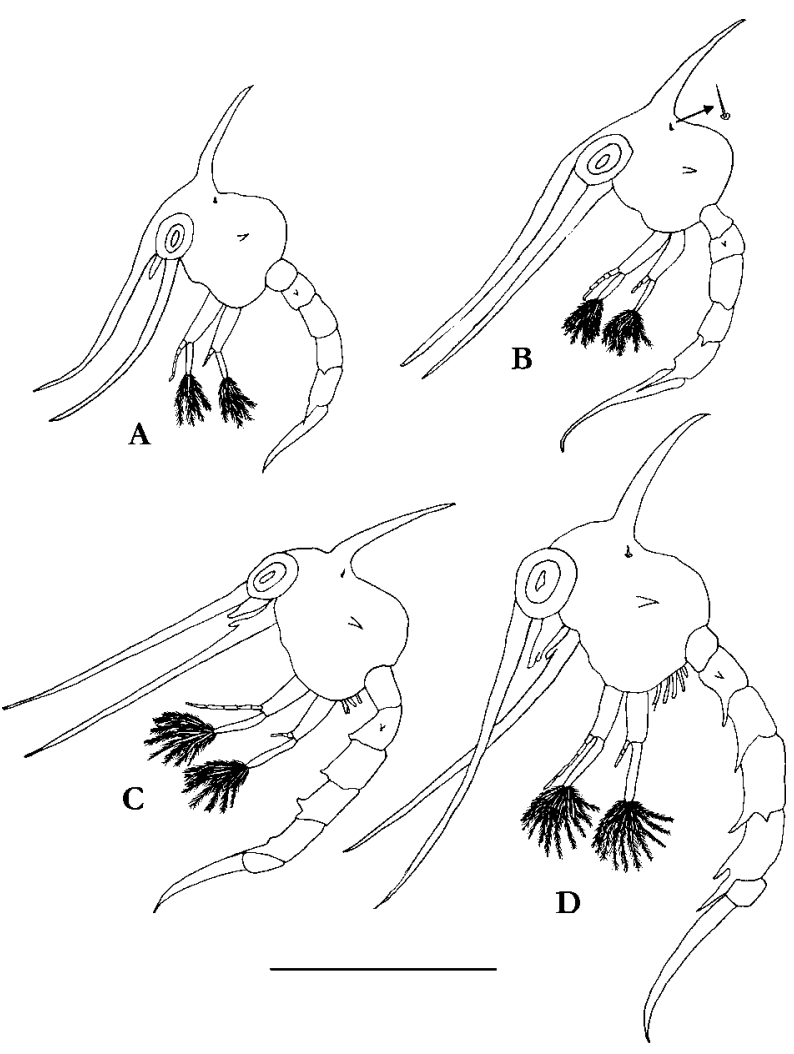

Fig. 2. Hexapanopeus caribbaeus (Stimpson, 1871). Lateral view: (a-d) zoea I to zoea IV. Scale bar, $1.0 \mathrm{~mm}$. 


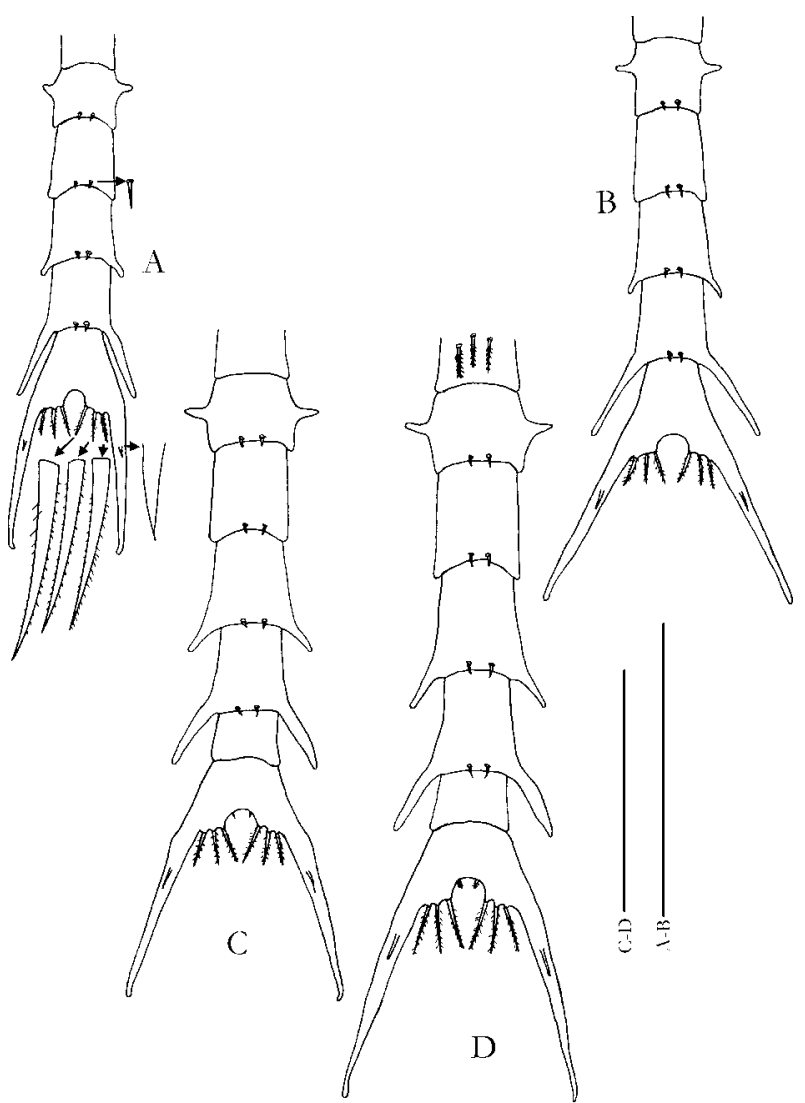

Fig. 3. Hexapanopeus caribbaeus (Stimpson, 1871). Dorsal view of abdomen: (a) zoea I (with magnification of setae of somite, setae and spine of telson); (b-d) zoea II to zoea IV. Scale bar, $0.5 \mathrm{~mm}$.

posterolateral projection, almost the same length of the somite 5 . Somite 1 without setae; somites $2-5$ with one pair of posterodorsal setae. Pleopod buds absent.

Telson (Figure 3a): Trapezoidal, with one dorsal spine on each fork branch. Three pairs of plumodenticulate setae on the inner furcal arch on each side.

Antennule (Figure 4a): Uniramous, conical; endopod absent; exopod unsegmented with two terminal aesthetascs and two terminal simple setae.

Antenna (Figure 4e): Protopodal process elongated, approximately equal in length to rostral spine; endopod absent; exopod unsegmented with one terminal simple setae.

Mandible (Figure 4i): Endopod palp absent; incisor process with small teeth. Molar process well developed with small teeth.

Maxillule (Figure 5a): Coxal endite with two subterminal and 4(5) terminal plumodenticulate setae. Basal endite with two terminal cuspidate setae, one subterminal and 2(3) terminal plumodenticulate setae. Endopod, two segmented with one plumodenticulate seta on the proximal segment and two subterminal and

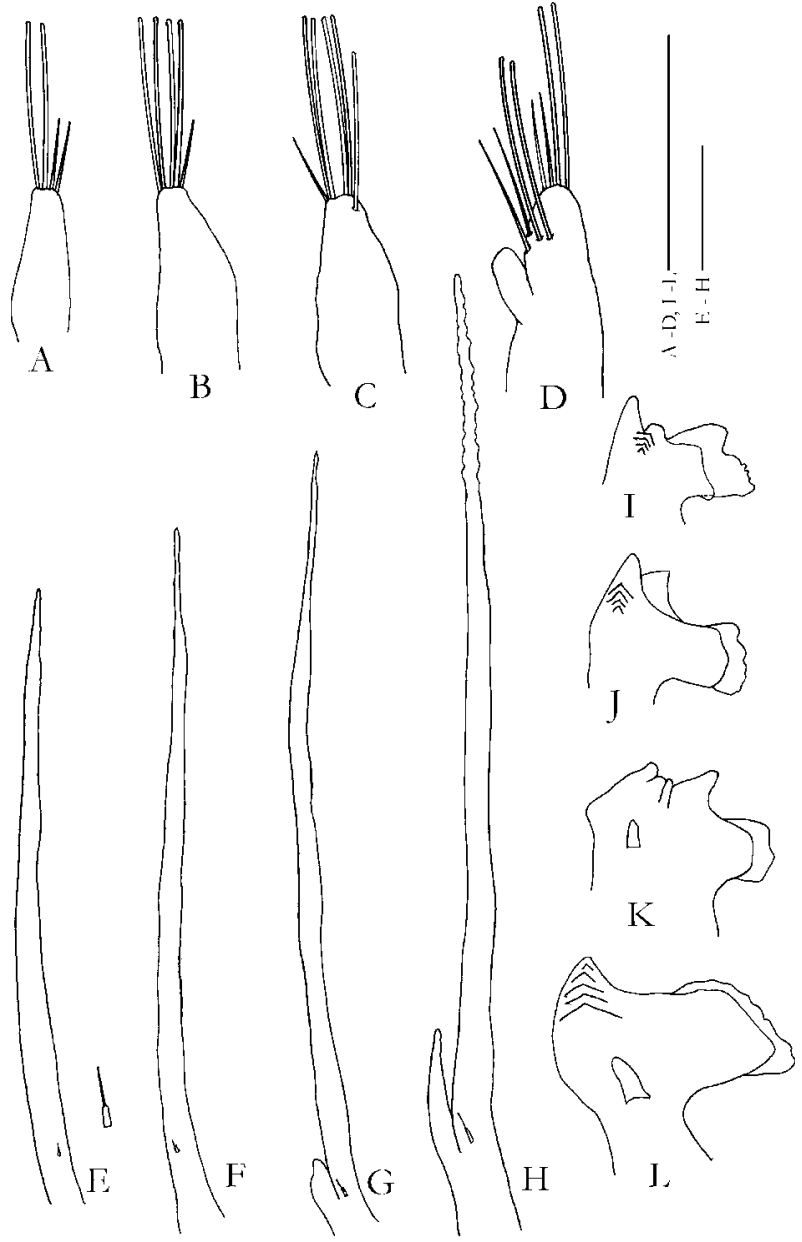

Fig. 4. Hexapanopeus caribbaeus (Stimpson, 1871). Antennule, (a-d) zoea I to zoea IV; antenna, $(\mathbf{e}-\mathbf{h})$ zoea I to zoea IV; mandible, $(\mathbf{i}-\mathbf{l})$ zoea I to zoea IV. Scale bar, $0.1 \mathrm{~mm}$.

four terminal plumodenticulate setae on the distal segment. Protopod without setae.

Maxilla (Figure 6a): Coxal endite bilobed, with one subterminal and 2(3) terminal plumodenticulate setae on the proximal lobe; distal lobe with one subterminal and two terminal plumodenticulate setae. Basal endite bilobed, with one subterminal plumodenticulate seta and four terminal plumodenticulate setae on the proximal lobe; distal lobe with one subterminal plumodenticulate seta and three terminal plumodenticulate setae. Endopod bilobed, with one subterminal and two terminal plumodenticulate setae on the proximal lobe and one subterminal and four terminal plumodenticulate setae on the distal lobe. Exopod (scaphognathite) with four marginal plumose setae, tapering to a sharp terminal process bearing microtrichia.

First maxilliped (Figure 7a): Basipod with 10 plumodenticulate setae arranged in four groups of 2,2,3,3 

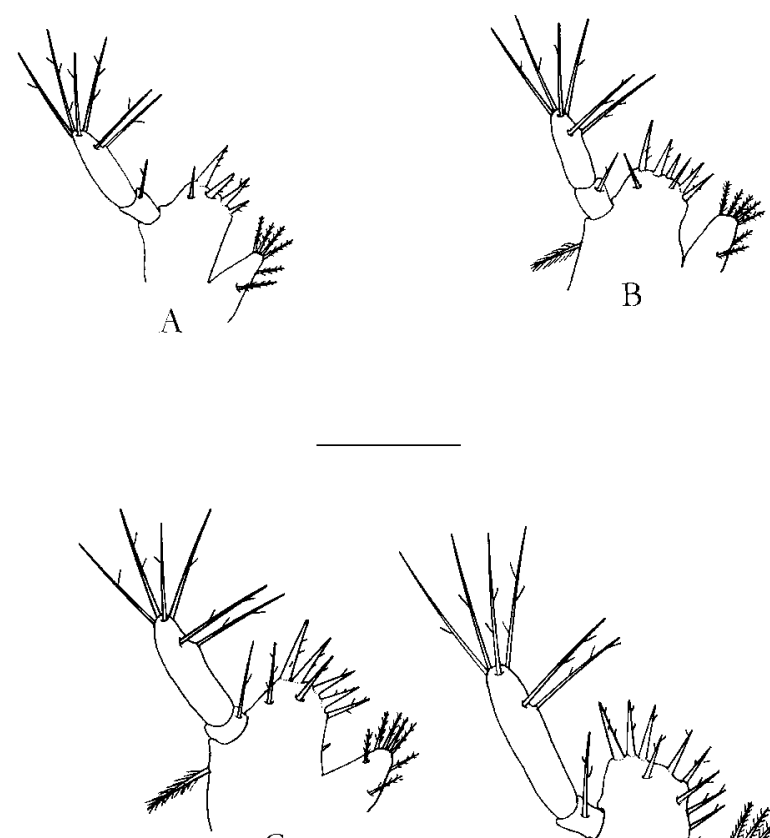

C

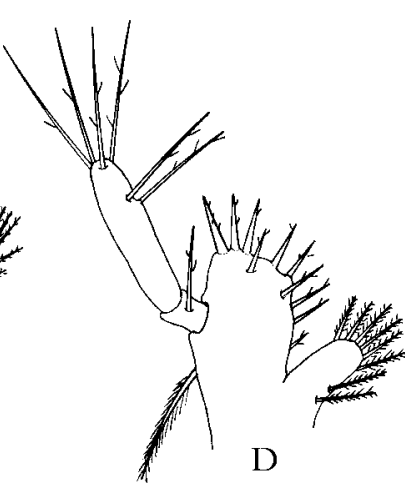

Fig. 5. Hexapanopeus caribbaeus (Stimpson, 1871). Maxillule, (a-d) zoea I to zoea IV. Scale bar, $0.1 \mathrm{~mm}$.

(proximal to distal). Endopod, five segmented with $3,2,1,2,4$ plumodenticulate setae (proximal to distal) and one simple seta on the fifth segment. Exopod with four long plumose natatory setae.

Second maxilliped (Figure 8a): Basipod with four plumodenticulate setae. Endopod, three segmented with 1,1,4 plumodenticulate setae (proximal to distal) and one simple seta on the third segment. Exopod with four long plumose natatory setae.

\section{Zoea II}

Carapace (Figure 2b): Eyes stalked. Otherwise unchanged. Abdomen (Figure 3b): Unchanged.

Antennule (Figure 4b): Unsegmented, with four terminal aesthetascs and one terminal simple seta.

Antenna (Figure 4f): Unchanged.

Mandible (Figure 4j): Unchanged.

Maxillule (Figure 5b): Coxal endite with 2(3) subterminal and 4(5) terminal plumodenticulate setae. Basal endite with three terminal cuspidate setae, three subterminal setae and one terminal plumodenticulate seta. Endopod similar to that of first zoea. Protopod with one pappose seta.

Maxilla (Figure 6b): Coxal endite with two subterminal and two terminal plumodenticulate setae on the proximal lobe; distal lobe with one subterminal and three
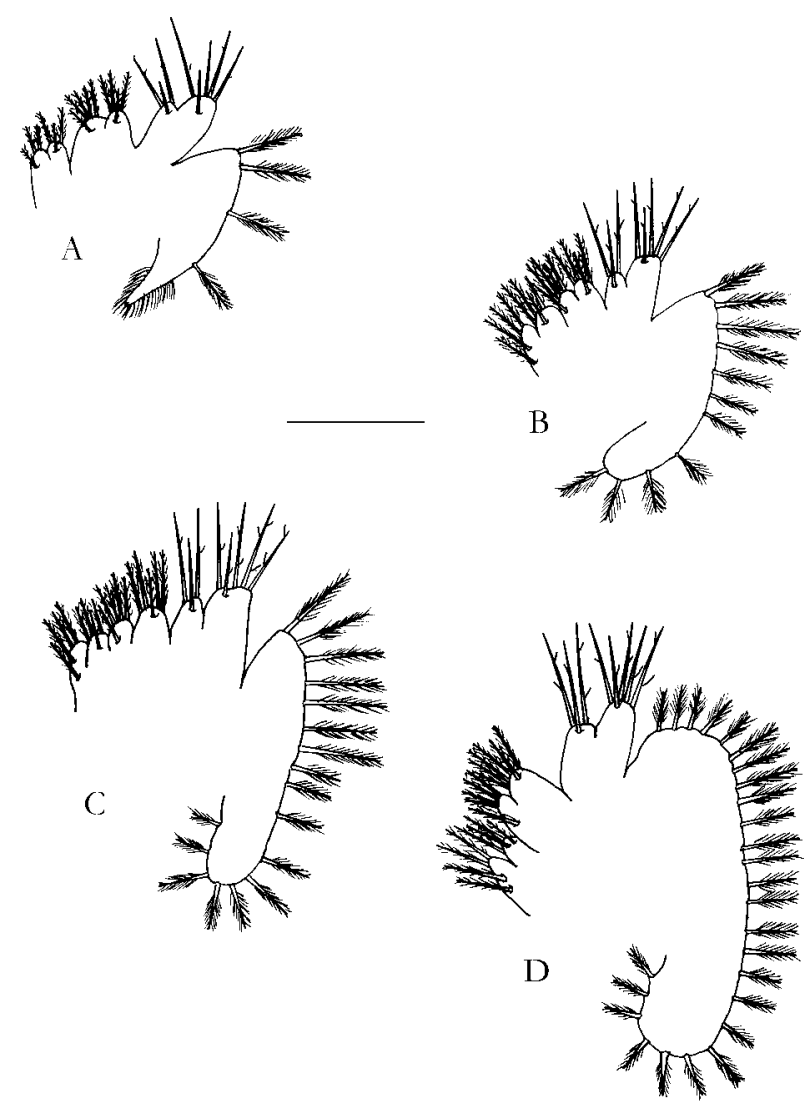

Fig. 6. Hexapanopeus caribbaeus (Stimpson, 1871). Maxilla, (a-d) zoea I to zoea IV. Scale bar, $0.1 \mathrm{~mm}$.

terminal plumodenticulate setae. Basal endite with one subterminal and four terminal plumodenticulate setae on the proximal lobe; distal lobe with one subterminal and three terminal plumodenticulate setae. Endopod similar to that of first zoea. Exopod with 11 marginal plumose setae.

First maxilliped (Figure 7b): Basipod and endopod unchanged. Exopod with six long plumose natatory setae.

Second maxilliped (Figure 8b): Basipod and endopod unchanged. Exopod with six long plumose natatory setae.

Zoea III

Carapace (Figure 2c): Unchanged.

Abdomen (Figure 3c): Now with six somites. Somite 6 smaller than the others. Pleopod buds present on somites $2-5$.

Telson (Figure 3c): Additional plumose setae on furcal arch on either side of median depression.

Antennule (Figure 4c): With one subterminal aesthetasc and 5(4) terminal aesthetascs; one terminal simple seta.

Antenna (Figure 4g): Endopod bud present. Otherwise unchanged. 


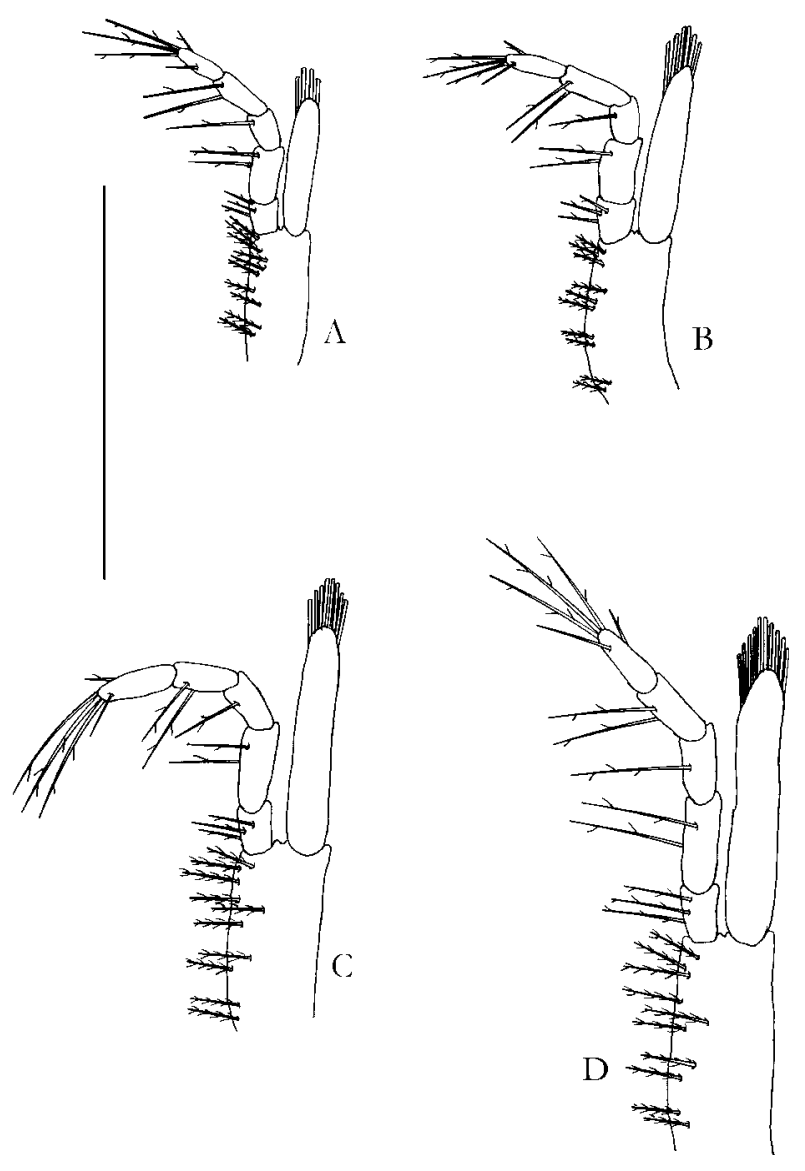

Fig. 7. Hexapanopeus caribbaeus (Stimpson, 1871). First maxilliped, (a-d) zoea I to zoea IV. Scale bar, $0.5 \mathrm{~mm}$.

Mandible (Figure 4k): Incisive and molar process more developed. Palp, rudimentary.

Maxillule (Figure 5c): Coxal endite with three subterminal plumodenticulate setae and 3(4) terminal plumodenticulate setae. Basal endite with three terminal cuspidate setae; three subterminal and two terminal plumodenticulate setae. Endopod and protopod unchanged.

Maxilla (Figure 6c): Coxal endite with two subterminal and two terminal plumodenticulate setae on the proximal lobe; distal lobe with one subterminal and three terminal plumodenticulate setae. Basal endite with one subterminal and four terminal plumodenticulate setae on the proximal lobe; distal lobe with one subterminal and four terminal plumodenticulate setae. Endopod similar to that of second zoea. Exopod with 17(18) marginal plumose setae.

First maxilliped (Figure 7c): Basipod and endopod unchanged. Exopod with eight long plumose natatory setae.

Second maxilliped (Figure 8c): Basipod and endopod unchanged. Exopod with eight long plumose natatory setae.

Third maxilliped: Rudimentary.
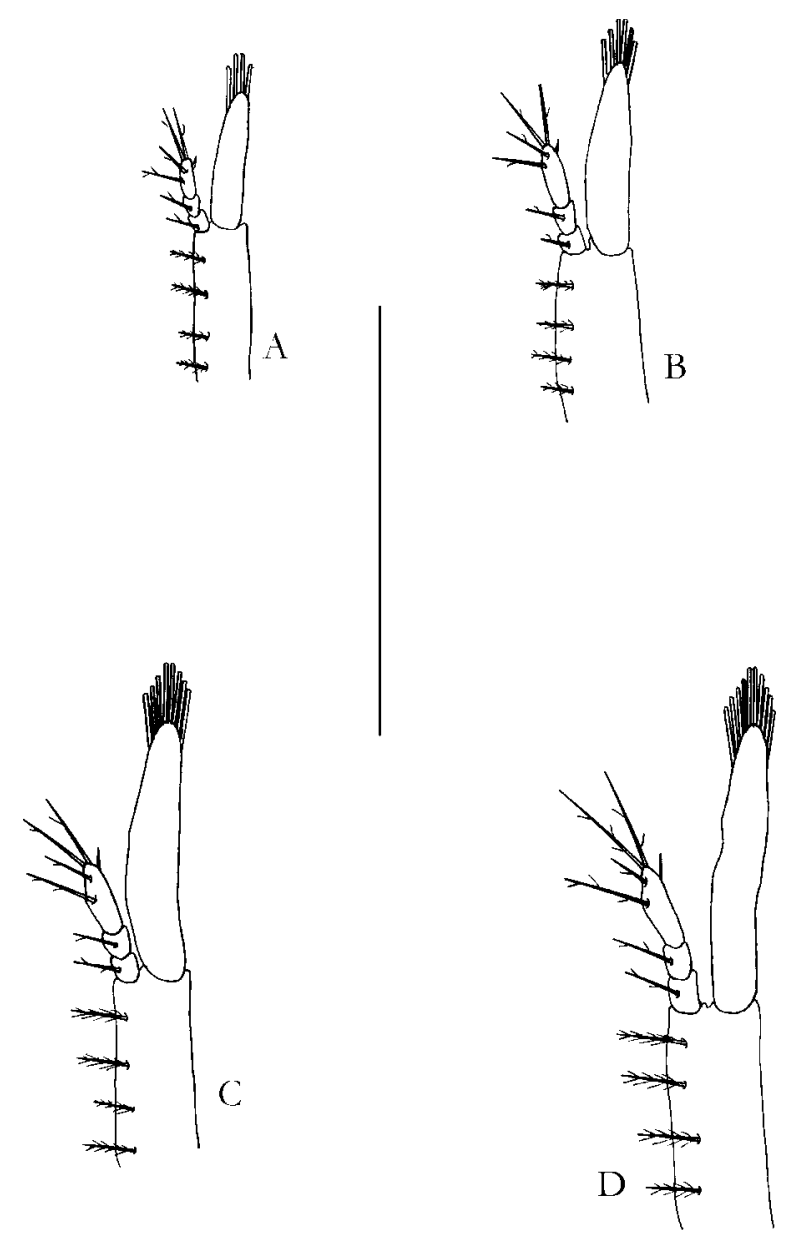

Fig. 8. Hexapanopeus caribbaeus (Stimpson, 1871). Second maxilliped, (a-d) zoea I to zoea IV. Scale bar, $0.5 \mathrm{~mm}$.

\section{Zoea IV}

Carapace (Figure 2d): Unchanged.

Abdomen (Figure 3d): Somite 1 with three dorsal plumose setae. Pleopods on somites 2-6 more developed. Telson (Figure 3d): Unchanged.

Antennule (Figure 4d): With 2(3) subterminal and 2(3) terminal aesthetascs; 2(1) subterminal and 2(1) terminal simple setae. Endopod present.

Antenna (Figure 4h): Endopod more developed. Otherwise unchanged.

Mandible (Figure 41): Teeth of the incisive and molar process distinct. Palp more developed.

Maxillule (Figure 5d): Coxal endite with two subterminal and six terminal plumodenticulate setae. Basal endite with three cuspidate setae and three subterminal and four terminal plumodenticulate setae. Endopod and protopod unchanged.

Maxilla (Figure 6d): Coxal endite with two subterminal and two terminal plumodenticulate setae on the proximal lobe; distal lobe with two subterminal and two terminal 

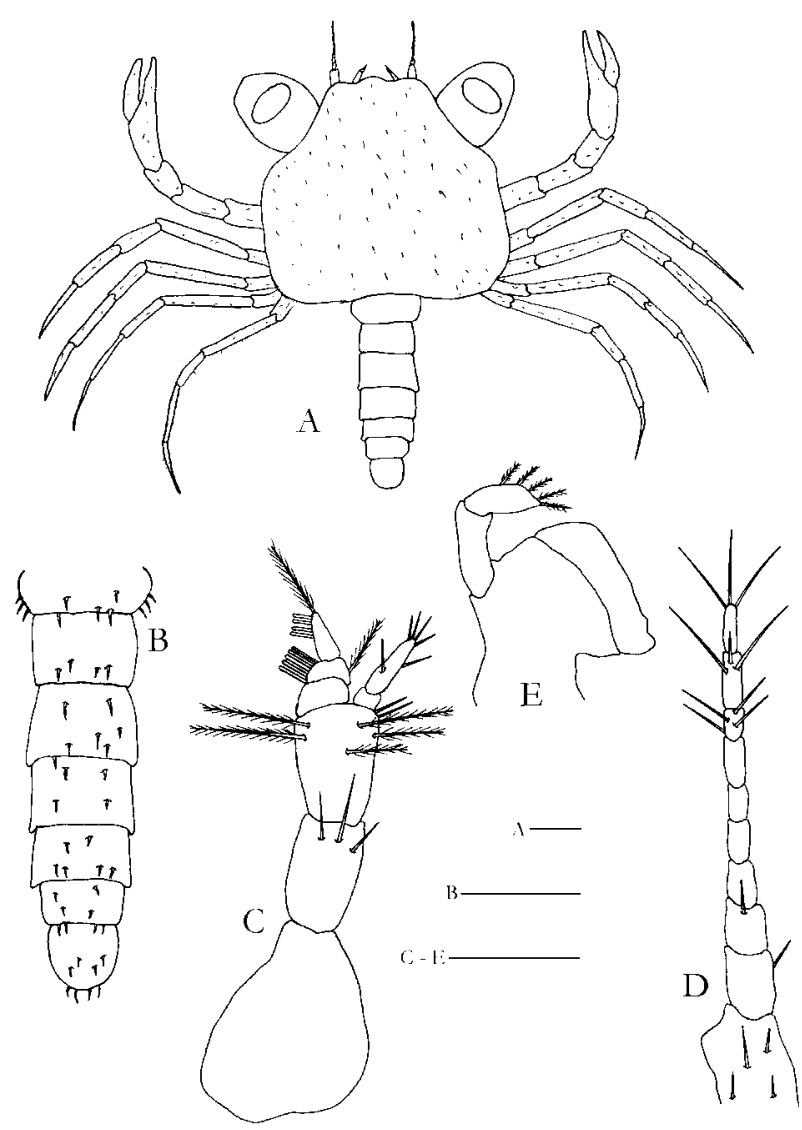

Fig. 9. Hexapanopeus caribbaeus (Stimpson, 1871). Megalopa, (a) dorsal view; (b) abdomen, dorsal view; (c) antennule; (d) antenna; (e) mandible. Scale bars: $1.0 \mathrm{~mm}(\mathbf{a}), 0.5 \mathrm{~mm}(\mathbf{b})$ and $0.1 \mathrm{~mm}(\mathbf{c}-\mathbf{e})$.

plumodenticulate setae. Basal endite with one subterminal and four terminal plumodenticulate setae on the proximal lobe; distal lobe with one subterminal and 5(4) terminal plumodenticulate setae. Endopod unchanged. Exopod with 26(27) marginal plumose setae.

First maxilliped (Figure 7d): Basipod unchanged. Endopod with 3,2,1,2,4(3) plumodenticulate (proximal to distal) setae and one subterminal simple seta on the fifth segment. Exopod with 10 long natatory plumose setae.

Second maxilliped (Figure 8d): Basipod and endopod unchanged. Exopod with 10 natatory plumose setae.

Third maxilliped: Biramous.

\section{Megalopa}

Carapace (Figure 9a): Subquadrate, surface covered by minute plumose and simple setae sparsely distributed. The rostrum is small, deflecting downward, not surpassing the first segment of the peduncle antennal. The eyes are stalked.

Abdomen (Figure 9b): With six somites plus the telson. Somites presented 9,4,6,5,6,4 (proximal to distal) small plumose setae sparsely on the dorsal region.

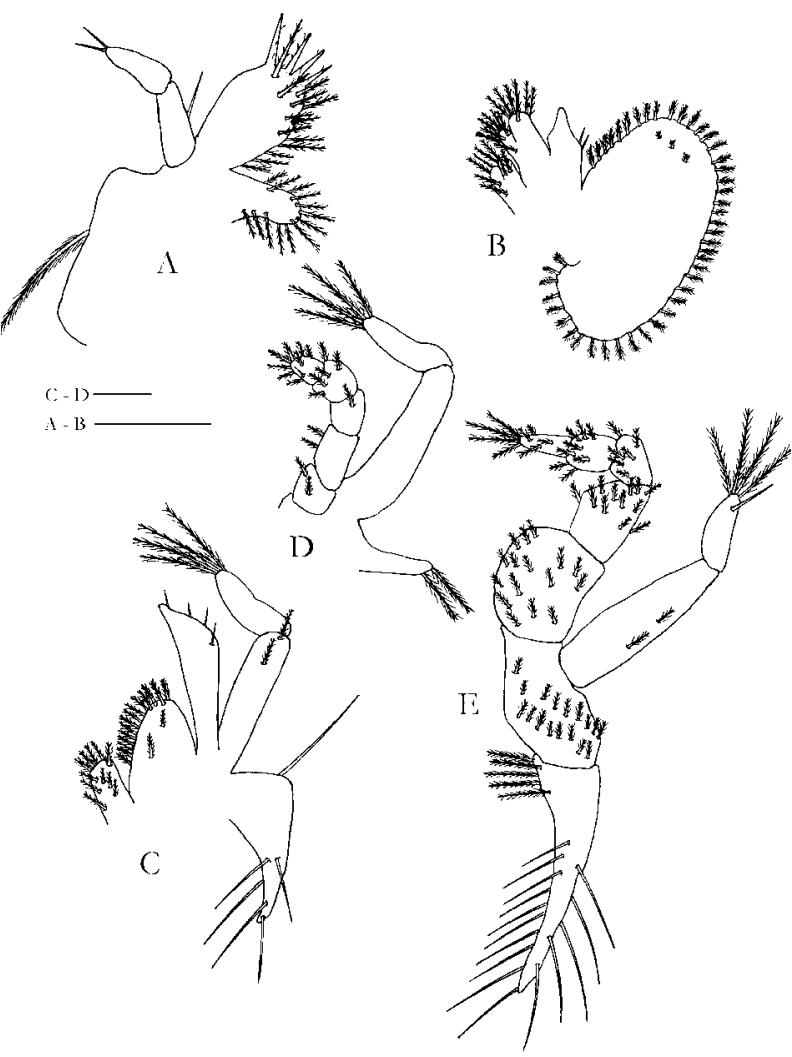

Fig. 10. Hexapanopeus caribbaeus (Stimpson, 1871). Megalopa, (a) maxillule; (b) maxilla; (c) first maxilliped; (d) second maxilliped; (e) third maxilliped. Scale bar, $0.1 \mathrm{~mm}$.

Telson (Figure 9b): With eight small plumose and simple setae on the dorsal posterior margin.

Antennule (Figure 9c): The antennullar peduncle is three segmented with the proximal segment naked; the median with 3(2) simple setae and distal segment with 2(3) small simple setae and 5(4) long plumodenticulate setae. Endopod (ventral flagellum) is two segmented with the proximal segment naked; distal segment with one median, one subterminal and four terminal simple setae. Exopod (dorsal flagellum), three segmented. Proximal segment is naked; the second with five aesthetascs and 3(1) plumodenticulate setae; the third with four aesthetascs and one plumodenticulate seta.

Antenna (Figure 9d): Consisting of a three-segmented peduncle with $4,1,1$ simple setae (proximal to distal). Flagellum, seven segmented with $0(1), 0,0,0(1), 4(3)$, 3(2),3 simple setae (proximal to distal).

Mandible (Figure 9e): Palp, two segmented, the first segment naked and the second segment with five plumodenticulate setae.

Maxillule (Figure 10a): Coxal endite with 8(7) subterminal and 5(6) terminal plumodenticulate setae. Basal endite with five cuspidate setae and seven subterminal and 


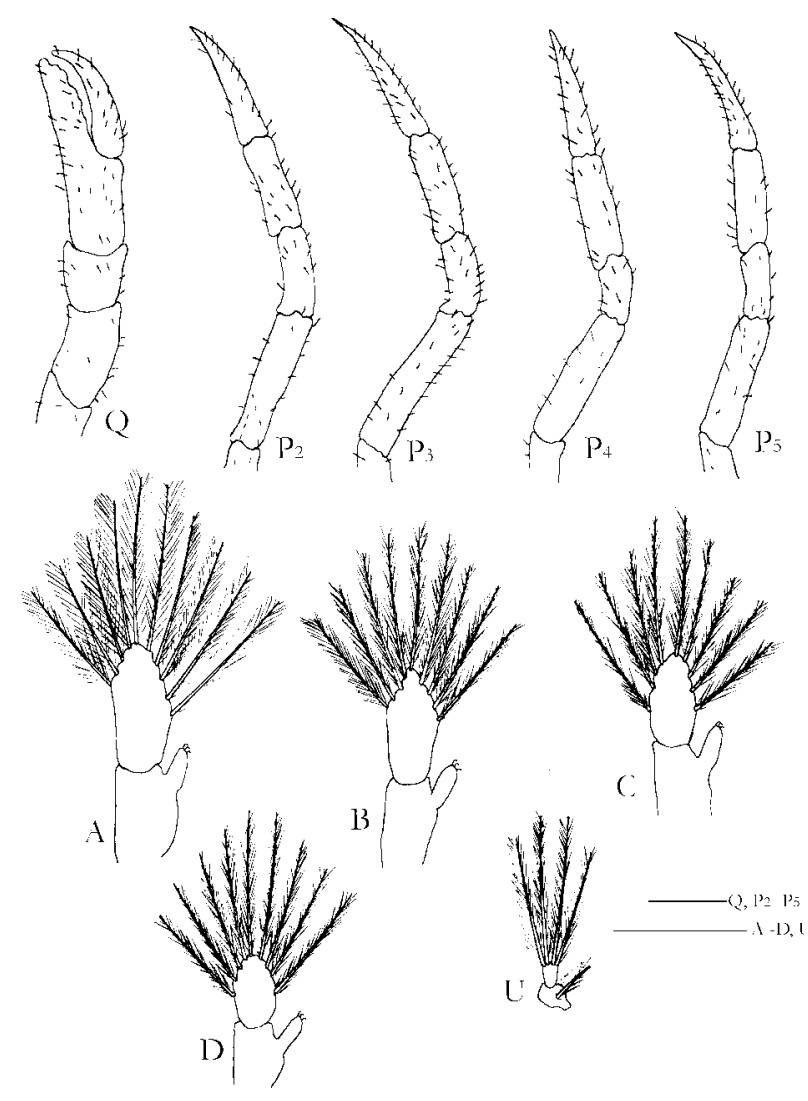

Fig. 11. Hexapanopeus caribbaeus (Stimpson, 1871). Megalopa, (Q $)$ chelipeds; (P2-P5) pereopods. (a-d) Pleopods; (U) uropods. Scales bar: 0.5 $\left(\mathbf{Q}, \mathbf{P}_{2}-\mathbf{P}_{5}\right) ; 0.1 \mathrm{~mm}(\mathbf{a}-\mathbf{e})$.

five terminal plumodenticulate setae. Endopod, two segmented with 1,2 simple setae (proximal to distal). Protopod with 1(2) pappose setae.

Maxilla (Figure 10b): Coxal endite with two subterminal and two terminal plumodenticulate setae on the proximal lobe; distal lobe with two subterminal and $2(3,4)$ terminal plumodenticulate setae. Basal endite with three subterminal and four terminal plumodenticulate setae on the proximal lobe; distal lobe with one subterminal and five terminal plumodenticulate setae. Endopod, unsegmented with 2(3) simple setae. Exopod (scaphognathite) with 45(42,47) marginal plumose setae and 3(1) plumose setae on the median surface.

First maxilliped (Figure 10c): Coxal endite with 6(5) subterminal and five terminal plumodenticulate setae. Basal endite with two subterminal and 14(13,15) terminal plumodenticulate setae. Endopod, unsegmented with 4(3) simple setae. Exopod, two segmented with two terminal plumodenticulate setae on the proximal segment and distal segment with four long-terminal plumose setae. Epipod with six long simple setae.
Second maxilliped (Figure 10d): Endopod, five segmented with 2(1),2,1,5(4),9(8-10) plumodenticulate setae (proximal to distal). Exopod, two segmented with 0(1) plumodenticulate setae on the proximal segment and 4(3) long plumose setae on the distal segment. Protopod with 2(1) plumodenticulate setae.

Third maxilliped (Figure 10e): Endopod, five segmented with 16(18), 12,6,8(7,9),8(6) plumodenticulate setae (proximal to distal). Exopod, two segmented with proximal segment with two plumodenticulate setae on the median surface; and distal segment with four plumodenticulate setae and one subterminal simple seta. Protopod with 17(16) plumodenticulate setae. Epipod with 5(6) plumose and 15(17) long simple setae.

Pereopods (Figure 11): Chelipeds are symmetrical, with small plumose setae sparsely distributed. The fixed finger with four small teeth in the inner margin and the mobile finger with one tooth. The pereopods are morphologically very similar to small setae sparsely distributed.

Pleopods (Figure 11a-d): Are present on segments 2-5, with a decrease in size, of the previous pair for the posterior. Exopod with 10(11),10(11),9(10,11),9(8,10) natatory plumose setae (proximal to distal). Endopod with three unciform setae.

Uropods (Figure 11u): Without endopod. Exopod, two segmented with one plumose seta on the proximal segment and 4(3) plumose setae on the distal segment.

\section{DISGUSSION}

Of the known Xanthoidea species that occur in the Brazilian waters with larval development, $H$. caribbaeus presented the highest rate of survival. It was also determined that the critical larval stage for $H$. caribbaeus is megalopa, while in $H$. paulensis the critical stage is the zoea IV. The average duration of the zoea and megalopa stages in $H$. caribbaeus was found to be shorter than the average duration of other Xanthoidea species that occur in the Brazilian coast. Factors such as temperature, type of food offered to the larvae, salinity and viability of the larvae used in the experiment may have influenced the fact that the larval stages were of short duration.

The zoea of Xanthoidea can be divided into six groups (see Rice, 1980; Gore et al., 1981; Martin, 1984 for a review) based on the ratio of the antennal exopod length to the propod length, i.e. larvae with less than a quarter of propod (group I); larvae about equal in length to or slightly longer than protopod (group II); larvae with about half the length of protopod (group III); larvae about half the length of protopod but tapering 
towards tip and with only two setae (group IV); larvae with less than $1 / 4$ of propod but tipped with three short terminal setae (group V); and larvae with exopod antennal absent (group VI). The antennal exopodite has a great importance phylogenetically (Aikawa, 1937), and this author used setae of other parts as additional characters to alter Hyman's (1925) proposal for three groups of Panopeidae. A well-developed antennal exopodite indicates a less closely derived condition (Wear, 1970). Given this, H. caribbaeus, which presents a very reduced antennal exopodite, is a more derived representative of the Panopeidae family and is associated with the genera Neopanope A. Milne, 1880, Lophopanopeus Rathbun, 1898, Rhithropanopeus Rathbun, 1898 and Eurytium Stimpson, 1859.

The Xanthoidea larvae show three lateral setae in the furca of the telson in all stages of the larval phase (Lebour, 1928). We did not observe a lateral spine but instead one dorsal spine in each branch of the telson fork in the larvae of $H$. caribbaeus. Hexapanopeus angustifrons and H. paulensis do not possess lateral or dorsal spines in the branches of the telson fork. The description of the three species of the genus Hexapanopeus that occur along the Brazilian coast presents differences related to the number of dorsal and lateral spines in each branch of the telson fork.

Among larvae of the Hexapanopeus genus occurring in the Brazilian coast, $H$. caribbaeus differs from the other species in having a pair of dorsolateral abdominal spines only on the second somite, while the other species possess a pair of dorsolateral abdominal spines on the second and third abdominal somite; Hexapanopeus caribbaeus shows a very long posterolateral projection in the fifth somite, while in the other species, the posterolateral projection is not very long.

Compared to megalopa stage, the species $H$. caribbaeus shows two segments on the endopod of the maxillule, while $H$. angustifrons and $H$. paulensis present one; there are $48(42,47)$ setations on the scafognatite of $H$. caribbaeus, while $H$. angustifrons and $H$. paulensis show $>50$.

\section{AGKNOWLEDGEMENTS}

We are grateful to Dr Gustavo Augusto S. Melo (Museu de Zoologia da Universidade São Paulo) for the identification of females. We thank Dr Fernando Marques of the Department of Zoology at the University of São Paulo, SP, Brasil for general support and for his valuable comments on the manuscript. This work was supported by CAPES Master Science fellowship awarded to the first author.

\section{REFERENGES}

Aikawa, H. (1937) Further notes on brachyuran larvae. Rec. Oceanogr. Work. Jpn., 9, 87-162.

Clark, P. F., Calazans, D. K. and Pohle, G. W. (1998) Accuracy and standardization of brachyuran larval descriptions. Invertebr. Reprod. Dev., 33, 127-144.

Costlow, J. D. Jr and Bookhout, C. G. (1966) Larval development of the crab Hexapanopeus angustifrons. Chesap. Sci., 7, 148-156.

Felder, D. L. and Martin J. W. (2003) Establishment a new genus for Panopeus bermudensis Benedict \& Rathbun, 1891 and several other xanthoid crabs from the Atlantic and pacific oceans (Crustacea: Decapoda: Xanthoidea). Proc. Biol. Soc. Wash., 116, 438-452.

Fransozo, A., Mantelatto, F. L. M. and Negreiros-Fransozo, M. L. (1990) Larval development of Hexapanopeus paulensis Rathbun, 1930 (Crustacea, Brachyura, Xanthidae) under laboratory conditions. Revta. Bras. Zool., 7, 21-45.

Gore, R. H., van Dover, C. L. and Wilson, K. A. (1981) Studies on decapod Crustacea from the Indian river region of Florida. XX. Micropanope barbadensis (Rathbun, 1921): The complete larval development under laboratory conditions (Brachyura, Xanthidae). 7. Crustac. Biol., 1, 28-50.

Hyman, O. W. (1925) Studies on the larvae of crabs of the family Xanthidae. Proc. U. S. Natl. Mus., 67, 1-22.

Ingle, R. W. (1992) Larval Stages of Northeastern Atlantic Crabs: An Illustrated Key. Chapman \& Hall, London, 363 pp.

Lebour, M. V. (1928) The larval stages of the Plymouth Brachyura. Proc. Zool. Soc. Lond., 473-560.

Martin, J. W. (1984) Notes and bibliography on the larvae of xanthid crabs, with a key the known xanthid zoeas of the western Atlantic and Gulf of Mexico. Bull. Mar. Sci., 34, 220-239.

Martin, J. W. and Davis G. E. (2001) An Updated Classification of the Recent Crustacea. In Science Series 39. Natural History Museum Los Angeles County, 132 pp.

Melo, G. A. S. (1996) Manual de Identificação dos Brachyura (Caranguejos e Siris) do litoral brasileiro. Plêiade/FAPESP, São Paulo, Brazil, 604 pp.

Pohle, G., Fransozo, A., Negreiros-Fransozo, M. L. et al. (1999) Larval Decapoda (Brachyura). In Boltovskoy, D. (ed.), South Atlantic Zooplankton. Brackhuys Publishers, Leiden, The Netherlands, pp. 1281-1351.

Rice, A. L. (1980) Crab zoeal morphology and its bearing on the classification of the Brachyura. Trans. Zool. Soc. Lond., 35, 271-424.

Rieger, P. J. (1997) Desenvolvimento larval de Uca (Minuca) mordax (Smith, 1870) (Crustacea, Decapoda, Ocypodidae), em laboratório. Trab. Oceanogr. Univ. Fed. PE, 25, 227-267.

Rieger, P. J. and Vieira, R. R. R. (1997) Desenvolvimento larval de Cyrtograpsus angulatus Dana, 1851 (Crustacea, Decapoda, Grapsidae), em laboratório. Revta. Bras. Zool., 14, 601-623.

Rieger, P. J., Vieira, R. R. R. and Santos, S. (1996) Hexapanopeus caribbaeus (Stimpson, 1871) novo registro de Brachyura (Decapoda, Xanthidae) para o litoral do Rio Grande do Sul, Brasil. Nauplius, 4, 169-170.

Schubart, C. D., Neigel, J. E. and Felder, D. L. (2000) Molecular phylogeny of mud crabs (Brachyura: Panopeidae) from the northwestern Atlantic and the role of morphological stasis and convergence. Mar. Biol., 137, 11-18.

Wear, R. G. (1970) Notes and bibliography on the larvae of Xanthid crabs. Pac. Sci., 24, 84-90. 